\title{
New measurements and compilation provide a 25,000 year view of global deep-sea radiocarbon
}

DR. PATRICK (HE/HIM) RAFTER ${ }^{1}$, WILLIAM R GRAY ${ }^{2}$, ANDREA BURKE ${ }^{3}, \mathrm{KASSANDRA} \mathrm{COSTA}^{4}$, JULIA GOTTSCHALK $^{5}$, MATHIS HAIN ${ }^{6}$, SOPHIA K.V. HINES ${ }^{7}$, JAMES W. B. RAE ${ }^{3}$, JOHN SOUTHON ${ }^{8}$ AND TIMOTHY

$$
\text { DEVRIES }^{9}
$$

${ }^{1}$ UC IRVINE

${ }^{2}$ Laboratoire des Sciences du Climat et de l'Environnement (LSCE/IPSL)

${ }^{3}$ University of St Andrews

${ }^{4}$ Woods Hole Oceanographic Institute

${ }^{5}$ Christian-Albrechts-Universität zu Kiel

${ }^{6}$ University of California - Santa Cruz

${ }^{7}$ Lamont-Doherty Earth Observatory of Columbia University

${ }^{8} \mathrm{UC}$ Irvine

${ }^{9} \mathrm{UCSB}$

Presenting Author: prafter@uci.edu

Here, using an updated compilation of published and newly measured marine microfossil radiocarbon $\left(\Delta^{14} \mathrm{C}\right)$, we examine the evolution of deep seawater $\Delta^{14} \mathrm{C}$ over the past 25,000 years. Our new dataset has $>1300$ more observations than prior work, including new measurements from throughout the deep Pacific as well as the first glacial-interglacial record of deep Indian Ocean $\Delta{ }^{14} \mathrm{C}$. The improved spatial distribution and number of observations allows us to investigate prominent theories of ocean basin ventilation changes (e.g., the "Bipolar See-Saw" and the "Sub-Arctic See Saw") from Heinrich Stadial 2 (»25,000 years BP) through the Last Glacial Maximum, deglaciation, and current interglacial warm period. 